\title{
Karaciğer Kitlelerinin Benign-Malign Ayrımında Difüzyon Ağırlıklı Sekansın Önemi
}

\author{
The Importance of Duffision-Weighted Imaging On Differentiation of Benign and Malign Liver Masses
}

\author{
Ebru Yılmaz Ayhan Yılmaz¹, Bülent Öner²
}

Kayseri Eğitim ve Arastırma Hastanesi Radyoloji Kliniği 2 Taksim Eğitim ve Araștrrma Hastanesi Radyoloji Kliniği

\section{Geliș tarihi : 18.04.2012 • Kabul tarihi: 14.02.2014}

\section{İletișim}

Dr.Ebru Yilmaz

GSM : 05326311983

E-mail :dr_ayyilmaz@yahoo.com

Kayseri Eğitim ve Araștırma Hastanesi Radyoloji Kliniği

Amaç: Karaciğerin fokal kitlelerinin benign-malign ayrımında difüzyon ağırlıklı görüntülemenin ve görünen katsayı (ADC) değerlerinin tanıya katkısını araștırdık.

Gereç ve Yöntem: Karaciğer kitlesi olan 34 hastaya kontrastlı inceleme öncesi difüzyon ağırlıkı MR görüntüleme sekansı uygulandı. 1,5 Tesla MR cihazında aksiyal planda, "single shot echoplanar spin" ile 3 farklı $b$ değerinde $\left(b=50, b=400, b=800 \mathrm{~s} / \mathrm{mm}^{2}\right)$ difüzyon gradiyentleri uygulanarak difüzyon ağırlıklı görüntüler elde edildi. $A D C$ haritaları üzerinden ortalama $1 \mathrm{~cm}$ boyutunda ROI yerleștirilerek ortalama ADC değerleri belirlendi.

Bulgular: Boyutu $1 \mathrm{~cm}$ 'den büyük olan 62 lezyon (46 benign, 16 malign) değerlendirildi. 46 benign lezyonun ortalama $A D C$ değeri $2.17 \pm 0.55 \times 10-3 \mathrm{~mm}^{2} / \mathrm{s}\left(0,98 \times 10^{-3} \mathrm{~mm}^{2} / \mathrm{s}-2,65 \pm 0.54 \mathrm{x}\right.$ $\left.10^{-3} \mathrm{~mm}^{2} / \mathrm{s}\right), 16$ malign lezyonun ortalama ADC değeri ise $0,84 \pm 0.40 \times 10^{-3} \mathrm{~mm}^{2} / \mathrm{s}(0,14 \pm 0.01 \mathrm{x}$ $10^{-3} \mathrm{~mm}^{2} / \mathrm{s}-1,32 \times 10^{-3} \mathrm{~mm}^{2} / \mathrm{s}$ ) idi.

Sonuç: Fokal karaciğer kitlelerinin benign-malign ayrımında difüzyon ağırıklı MR görüntüleme ve $A D C$ değerlerinin karșılaștııılması ek bilgiler sağlamakta, özellikle IV kontrast veremediğimiz hastalarda ayırıcı tanıda bize yardımcı olmaktadır.

Anahtar Sözcükler: Karaciğer kitlesi, Difüzyon ağırlıkı MR görüntüleme, ADC değeri

Purpose: We investigated the diagnostic value of diffusion weighted imaging and apperent diffusion coefficient (ADC) mapping on differential diagnosis of benign and malignant focal liver masses.

Materials And Metods: Diffusion - weighted MR imaging sequence was applied on 34 patients with a focal liver mass before contrast enhanced imaging. Diffusion - weighted images were obtained by applying 3 diffusion gradients at $b$ level $\left(b=50, b=400, b=800 \mathrm{~s} / \mathrm{mm}^{2}\right)$ with single shot echo-planar spin in axial plan in 1.5 Tesla MR tool. Average ADC values were determined by placing $\mathrm{ROI}$ at the size of $1 \mathrm{~cm}$ on average over ADC maps.

Results: 62 lesions ( 46 benign, 16 malign) greater than $1 \mathrm{~cm}$, in size were evaluated. Average $A D C$ value of 46 benign lesions was $2.17 \pm 0.55 \times 10-3 \mathrm{~mm}^{2} / \mathrm{s}$ and varied between $(0,98 \times 10-3$ $\left.\mathrm{mm}^{2} / \mathrm{s} 2.65 \pm 0.54 \times 10^{-3} \mathrm{~mm}^{2} / \mathrm{s}\right)$ and average $A D C$ value of 16 malignant lesion was $0.84 \pm 0.40$ $\times 10^{-3} \mathrm{~mm}^{2} / \mathrm{s}\left(0.14 \times 1010^{-3} \mathrm{~mm}^{2} / \mathrm{s}-1.32 \times 10^{-3} \mathrm{~mm}^{2} / \mathrm{s}\right)$.

Conclusion: Diffusion - weighted MR imaging and comparison of $A D C$ values provide additional information in differentiating benign and malignant focal liver masses and particularly help us in differential diagnosis of patients to whom we cannot deliver IV contrast.

Key Words: Liver mass, Diffusion-weighted magnetic resonance imaging, ADC value.

Difüzyon, dokudaki su moleküllerinin rastlantisal mikroskopik hareketidir. Difüzyon ağırlıklı görüntüleme (DAG) ile su moleküllerinin ekstraselüler, intraselüler ve intravasküler alandaki hareketleri ölçülür (1). DAG harekete son derece duyarlıdir ve solunumsal, kardiak, peristaltik fizyolojik hareketler görüntü kalitesini belirgin şekilde bozar ve değerlendirmeyi güçleştirir. Bu nedenle DAG uzun yıllar sadece beyin görüntüleme ile sınırlı kalmıştır. Hızlı manyetik rezonans (MR) görüntüleme yöntemi olan eko-planar görüntülemenin (hızlı gradiyent eko sekansi) geliştirilmesi ile konvansiyonel sekanslardaki uzun görüntüleme süreleri ve buna bağlı artefaktlar ortadan kalkmış ve 
DAG abdominal organların değerlendirilmesinde kullanılır hale gelmiştir (2).

Görünen katsayı (ADC) değeri difüzyon gradiyenti uyguladiktan sonra görülen sinyal kaybının harita üzerinde işaretlenmesi sonucu difüzyonun matematiksel bir hale getirilmesidir (3). Siklıkla klinik MR sistemleri tarafından otomatik olarak yapilmaktadir. Düşük ADC değerleri (ADC'de hipointens, DAG'da hiperintens) malignite lehine, yüksek ADC değerleri (ADC'de hiperintens, DAG'da hipointens veya hiperintens) benignite lehine bulgudur. Daha önceki çalışmalarda da (4-6) karaciğerin fokal kitlelerinin ADC değerleri karşılaştırılarak benign ve malign lezyonları ayırmada eşik değer araştırılmıştır.

Çalışmamızdaki amacımız karaciğerin fokal kitlelerini intravenöz (IV) kontrast madde vermeden konvansiyonel sekanslardaki sinyal özelliklerine ek olarak DAG'deki sinyal özellikleri ve ADC değerleri ile ayırt edebilmektir.

\section{GEREÇ VE YÖNTEM}

Çalışmamız Mart 2008- Şubat 2010 tarihleri arasında ünitemize başvuran, ultrasonografi (US) ve bilgisayarlı tomografide (BT) karaciğerde kitle saptanan 18 yaş ve üzeri 34 hastada toplam 62 lezyondan oluşmaktadır (Tablo 1).

34 hastanın 24'ü erkek, 10'u kadındı. Hastaların yaş ortalaması 58 (31-83) idi.

\section{Hastalar}

Kist Hidatik : Yedi hastada toplam yedi kist hidatik lezyonu (ortalama çap 7,4 cm; aralık 5,4-12 cm) değerlendirildi. Çalışmamızda yer alan kist hidatik vakalarından tipik kız vezikülleri içeren dört hastada
US ile tanı koyuldu. Geri kalan üç vakada radyolojik bulgular serolojik verilerle (Ech-IHA pozitifliği) desteklenerek tanı doğrulandı.

Hemanjiom: 12 hastada toplam 28 hemanjiom (ortalama çap $3,7 \mathrm{~cm}$; aralık 1,0-7,6 cm) değerlendirildi. Hemanjiom tanısı kontrastlı MR görüntülemede tipik kontrastlanma paternleri (arteryal ve portal fazda periferden santrale doğru giderek artan nodüler, kesintili, halkasal tarzda ve geç fazda homojen kontrastlanma) ile konuldu $(7,8)$.

Metastaz: Yedi hastada 13 metastatik lezyon (ortalama çap 2,1 cm; aralık 1,3-4 cm) değerlendirildi. Metastazlardan 11 tanesi primer malignitesi bilinen (altı kolon, üç lenfoma bir meme, ve bir pankreas kanseri) olgularda takip sırasında ortaya çıkan ve büyüyen multipl lezyonlar olarak tespit edildi. Geri kalan iki lezyonun primeri bilinmiyordu ve biyopsi sonrası adenokarsinom metastazı olarak bildirildi.

Hepatoselülerkarsinom (HCC): Üç hastada toplam üç HCC kitlesi (ortalama çap 3,5 cm; aralık 2-5 $\mathrm{cm})$ değerlendirildi. MR görünümleri ve kontrastlanma paternleri ile hepatoselüler karsinom ön tanısı alan ve $\alpha$ fetoprotein seviyesi yüksek olan üç vakamıda tanı biyopsi ile doğrulandı. Tüm HCC vakaları hepatit B'li hastalarda sirotik zeminde gelişmiş olup iki vakada soliter lezyon, bir vakada diffüz tutulum vardi.

Fokal Nodüler Hiperplazi (FNH): Çalışmamızda bir FNH lezyonu (çap, 4,7 cm) değerlendirildi. MR görüntüleme sinyal özellikleri ve kontrastlanma paterni ile fokal nodüler hiperplazi ön tanısı düşünülen hastada tanı radyonüklid görüntüleme ile desteklendi ancak biyopsi yapilamadi.

Abse: Çalı̧̧mamızda bir piyojenik abse lezyonu (çap $1,5 \quad \mathrm{~cm}$ ) değerlendirildi. Kolesistektomi sonras1 10. günde karaciğer sağ lob posterior inferior segmentte T2 ağırlıklı görüntülerde periferik ödemi izlenen, kontrastl çalışmalarda duvarı kontrast tutan lezyon saptand. Klinik ve laboratuvar bulguları da abseyi destekleyen olguda drenaj yapild ve piyojenik abse olarak tanı aldı.

Kist: Üç hastada toplam dokuz kist (ortalama çap, 2,3 cm; aralık 1,8-3,2 $\mathrm{cm})$ değerlendirildi. Basit karaciğer kistleri tipik US, BT ve MR bulguları ile tanı aldı.

\section{MR Görüntüleme}

İncelemeler 1,5-T MR cihazı (Avanto; Siemens) ile faz siralı sargilar

Tablo 1. Lezyonların sayılarına göre dağılımı

\begin{tabular}{|l|l|}
\hline MALIGN LEZYONLAR & LEZYON SAYISI \\
\hline HCC $^{*}$ & 3 \\
\hline Metastaz & 13 \\
\hline
\end{tabular}

\begin{tabular}{|l|l|}
\hline BENIGN LEZYONLAR & LEZYON SAYISI \\
\hline Basit kist & 9 \\
\hline Hemanjiom & 28 \\
\hline Kist Hidatik & 7 \\
\hline FNH** & 1 \\
\hline Piyojenik abse & 1 \\
\hline
\end{tabular}

${ }^{*}$ HCC: Hepatesülüler karsinam

${ }^{* *}$ FNH:Fokal Nodüler Hiperpilazi 
kullanılarak gerçekleştirildi. Rutin incelemede; aksiyel planda yağ baskılı TSE T2 ağırlıklı (TR/TE: 1000/85 ms, yatış açısı: 150; kesit kalınlığ $14 \mathrm{~mm}$; FOV:400 $\mathrm{mm}$ ), gradiyent eko aynı faz ve ters faz T1 ağırlıklı (TR/TE: 209/4,2 (aynı faz), TR/TE: 209/2,38 (ters faz); yatış açısı: 70;matrix 320x192;kesit kalınlığ1: 4mm; FOV: 400mm) ve kontrastlı T1 ağırlıklı görüntüler kilogram başına $0,10 \mathrm{mmol}$ gadobenat dimeglumin (Multihance; Bracco S.p.A. Milanİtalya) verilerek elde edildi. Kontrastlı kesitler alınmadan önce difüzyon ağırlıklı MR incelemesi yapıldı. Difüzyon ağırlıklı sekanslar (TR/TE: 3300/83msn, yatış açısı: 90 ,kesit kalınlığı: $4 \mathrm{~mm}$; FOV: $410 \mathrm{~mm}$, nefes tutmali) aksiyel planda 3 farklı b değerinde (b: $50 \mathrm{~s} / \mathrm{mm}^{2}, \mathrm{~b}: 400 \mathrm{~s} / \mathrm{mm}^{2}, \mathrm{~b}: 800$ $\mathrm{s} / \mathrm{mm}^{2}$ ) gradiyentler uygulanarak elde edildi. ADC haritaları cihaz tarafindan otomatik olarak oluşturuldu ve tüm lezyonların ortalama ADC değerleri bu haritalar üzerinden ölçüldü.

\section{Görüntülerin Değerlendirilmesi}

Görüntülerin değerlendirilmesi tecrübeli iki radyolog tarafından gerçekleştirildi. Radyologlar, değerlendirilme öncesi hastaların BT ve US sonuçlarını incelediler. Difüzyon ağırlıklı sekanslarda rezolüsyonun kisitlı olması sebebi ile değerlendirmeye bir cm'den büyük lezyonlar dahil edildi. Tüm lezyonlarin ortalama ADC değerleri iş istasyonunda $\mathrm{ADC}$ haritaları üzerinden ölçüldü. Ölçümler lezyonlar üzerine ortalama $1 \mathrm{~cm}$ çapında dairesel ROI'ler yerleştirilerek yapıldi. Büyük lezyonlarda 3 ayrı ROI ölçümünün ortalaması alındı. Özellikle kistik komponenti olan solid lezyonlarda ölçümün kontrast tutan solid alanlardan yapılmasına dikkat edildi. Bir $\mathrm{cm}$ boyutundaki lezyonlarda tüm lezyonu içine alacak şekilde ROI yerleştirilerek tek ölçüm yapıldı.Tüm ölçümlerde ROI ile işaretlenen alanın komşu karaciğer parankimine taşmamasına dikkat edildi.

Benign ve malign karaciğer fokal kitlelerinin ADC değerleri belirlenerek karşılaştırıldı. İstatiksel analiz SPSS (Version 15.0, Chicago, Illionis) paket programı ile yapild. Verilerin normallik sinamaları Shapiro-Wilk testi ile test edildi. Gruplar arasi karşılaştırmalar bağımsız iki örneklem t testi ile yapild. Anlamlılık düzeyi $\rho=0.05$ kabul edildi.

\section{BULGULAR}

Lezyonların ADC ölçümleri sonucunda 46 benign lezyonun ortalama ADC değeri 2,17 $\pm 0,55 \mathrm{x}$ $10^{-3} \mathrm{~mm}^{2} / \mathrm{s}$ olarak hesapland 1 . Benign lezyonlara ait ADC değerleri $0.98 \times 10^{-3}$ ile $2,65 \pm 0,54$ $x \quad 10^{-3} \quad \mathrm{~mm}^{2} / \mathrm{s}$ arasinda değişmekteydi (Tablo 2). En

Tablo 2. Lezyon tiplerine göre ortalama ADC değerleri.

\begin{tabular}{lc}
\hline \hline Lezyon tipi & Ortalama ADC $\left(\mathrm{mm}^{2} / \mathrm{s}\right)$ \\
\hline Benign lezyonlar & $2,65 \pm 0,54$ \\
Basit kist $(\mathrm{n}=9)$ & 0,98 \\
Piyojenik abse $(\mathrm{n}=1)$ & $1,98 \pm 0,38$ \\
Hemanjiom $(\mathrm{n}=28)$ & 1,46 \\
FNH $(\mathrm{n}=1)$ & $2,56 \pm 0,48$ \\
Kist hidatik $(\mathrm{n}=7)$ & \\
& \\
Malign lezyonlar & $1,14 \pm 0,13$ \\
HCC $(\mathrm{n}=3)$ & \\
Metastaz & $0,92 \pm 0,12$ \\
Kolorektal kanser metastazı $(\mathrm{n}=6)$ & 1,32 \\
Pankreas bașı kanseri metastazı $(\mathrm{n}=1)$ & $0,14 \pm 0,01$ \\
Lenfoma ( $=3$ ) & 0,93 \\
Meme kanseri metastazı $(\mathrm{n}=1)$ & $0,88 \pm 0,46$ \\
Primeri belli olmayan metastaz $(\mathrm{n}=2)$ &
\end{tabular}

yüksek ADC değeri basit kistlere aitken, en düşük ADC değeri ise piyojenik abseye aitti (Şekil 1).
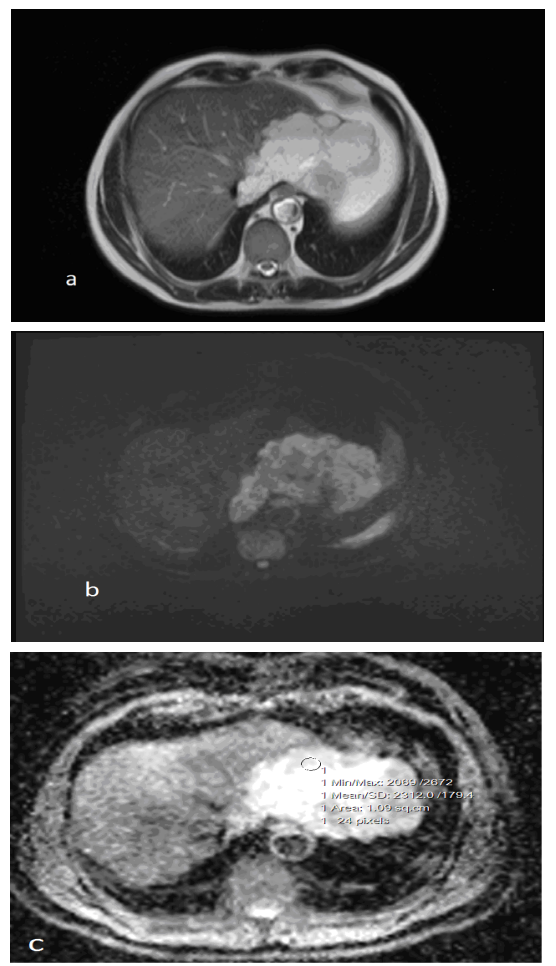

Şekil 1. Karaciğer sol lobda dev hemanjiom. T2 AG'de (a); hiperintens, b $800 \mathrm{~s} / \mathrm{mm}^{2}$ DAG'de (b) ve ADC haritasında (c) hiperintens kitle. Ortalama ADC değeri $2,312 \times 10^{3} \mathrm{~mm}^{2} / \mathrm{s}$ olarak ölçüldü.

Tüm kist hidatik vakalarının ortalama ADC değeri, 2,56 $\pm 0,48 \times 10^{-3}$ $\mathrm{mm}^{2} / \mathrm{s}$ dir (Şekil 2). Çalışmamızda yer alan yedi kist hidatik vakası US'de yapilan Gharbi sinıflamasina (7) göre; dört vaka tip -3, bir vaka tip -2 , bir vaka tip -4 ve bir vaka tip 5 kist hidatik olarak sınıflandirıldı. Hidatik kistler difüzyon ağırlıklı sekanslarda düşük $b$ değerinde hiperintens, yüksek $b$ değerlerinde (b:400 ve b:800) hipointens, ADC haritasında ise hiperintens olarak izlenmiş olup difüzyon kısıtlılığı saptanmamıştır. Düşük b değerinde hiperintens olmaları hemanjiomlar ve basit kistlerde olduğu gibi T2 etkisinin devamı olarak değerlendirildi $(1,8)$. 


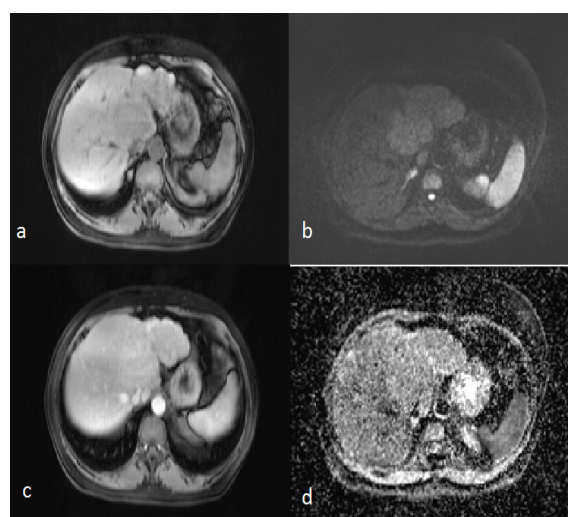

Şekil 2. Karaciğer sağ lobunu dolduran kist hidatik. Koronal planda HASTE (a),aksiyel planlarda T1 AG (b), b $800 \mathrm{~s} / \mathrm{mm}^{2}$ DAG (c) ve $A D C$ haritası (d). DAG'de hipointens, ADC haritasında hiperintens sinyal özelliğinde difüzyon kısıtlılığı izlenmeyen multiseptalı kistik kitlede ortalama ADC değeri 2,474 x 10 ${ }^{3} \mathrm{~mm}^{2} / \mathrm{s}$ olarak ölçüldü.

Çalışmamızda fokal nodüler hiperplazili bir vaka yer almakta olup ortalama ADC değeri $1.463 \mathrm{x}$ $10^{-3} \mathrm{~mm}^{2} / \mathrm{s}$ ölçülmüştür. (Şekil 3). Komşu karaciğer parankimi ortalama ADC değeri ise $1.514 \mathrm{x}$ $10^{-3} \mathrm{~mm}^{2} / \mathrm{s}$ olarak ölçüldü.

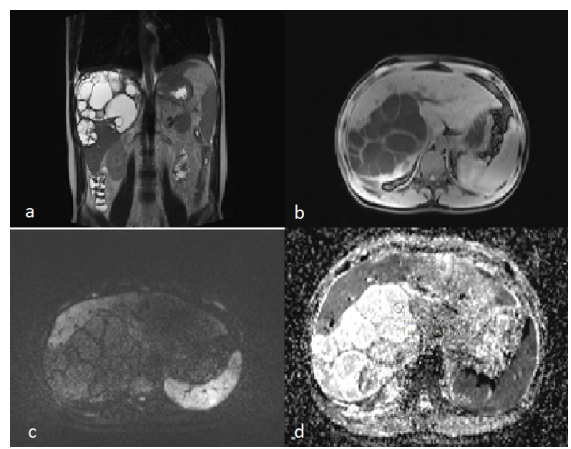

Şekil 3. Karaciğer sol lobda FNH. T1 AG (a), kontrastlı arteryal faz T1 AG (b), b $400 \mathrm{~s} /$ $\mathrm{mm}^{2}$ DAG (c) ve ADC haritası (d). T1 AG'de izointens, erken arteryal fazda globüler tarzda kontrast tutan, santral kesimde kontrast tutmayan hipointens alan barındıran kitle. DAG'de ve ADC haritasında hafif hiperintens yani difüzyon kısıtılığı göstermiyor.
16 malign lezyonun ortalama $\mathrm{ADC}$ değeri $0,84 \pm 0,40 \times 10^{-3} \mathrm{~mm}^{2} / \mathrm{s}$ olarak hesaplandi. Malign lezyonlara ait ADC değerleri 0,14 $\pm 0.01 \times 10^{-3}$ ile $1,32 \times 10^{-3} \mathrm{~mm}^{2} / \mathrm{s}$ arasında değişmekteydi (Tablo 2). En yüksek $\mathrm{ADC}$ değeri pankreas başı metastazına aitken, en düşük $\mathrm{ADC}$ değeri ise lenfomaya aitti.

Malign lezyonlardan metastazların yedi tanesinin santrallerinde nekroze kistik alanlar mevcuttu. $\mathrm{Bu}$ lezyonlardan $\mathrm{ADC}$ ölçümü yapılırken özellikle kontrastlı incelemelerde kontrast tutan ve difüzyon kısıtlllığı izlenen solid alanlardan ölçüm yapılmasına dikkat edilmiştir (Şekil 4).

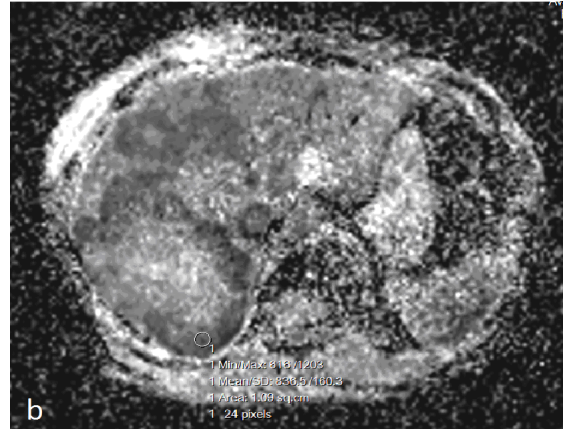

Şekil 4. Rektosigmoid bölgede invaziv adenokarsinom ve çok sayıda karaciğer metastazları olan 69 yaşında erkek hastada, karaciğer kitlelerinin santralinde koagülasyon nekrozu izlendi. Aksiyel planda b $800 \mathrm{~s} / \mathrm{mm}^{2}$ DAG (a) ve ADC haritası (b). Santral nekroze kısım ADC haritasında hiperintens iken periferik solid kısımlarda belirgin difüzyon kısıtlıığı mevcut. Bu difüzyon kısıttııı̆ı olan alanlardan yapılan ölçümde ADC değeri $0,836 \times 10^{-3} \mathrm{~mm}^{2} / \mathrm{s}$ olarak ölçüldü.

Tüm metastatik lezyonların ortalama ADC değerlerini karşılaştırdığımızda en düşük ADC değeri lenfoma lezyonlarından ölçülmüştür (Şekil 5).
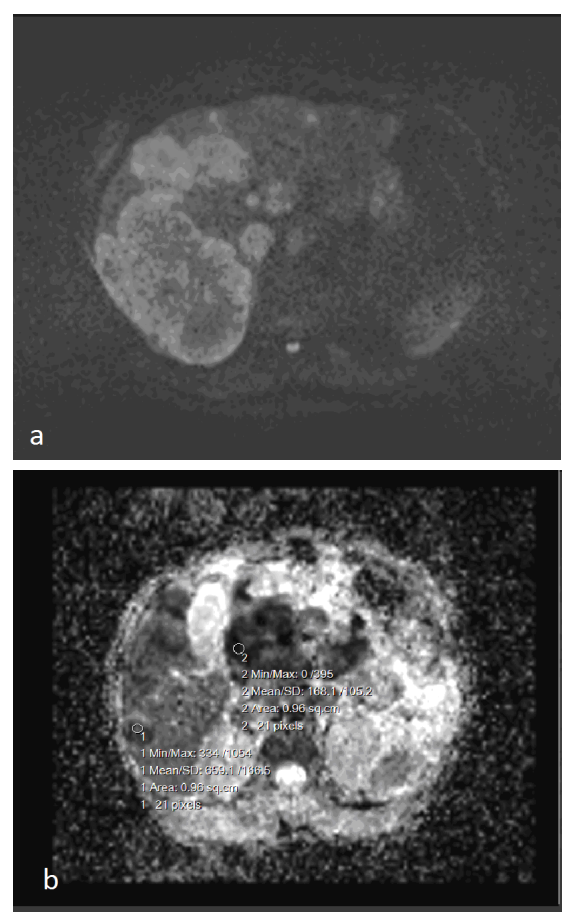

Şekil 5. Non-Hodgkin Lenfoma tanılı 54 yaşında erkek hastada multipl karaciğer kitleleri. Aksiyel planda b $800 \mathrm{~s} / \mathrm{mm}^{2}$ DAG (a)'de hiperintens ve ADC haritasında (b) hipointens, belirgin difüzyon kısıtlıığı izlenen kitlelerden yapılan ADC ölçümleri ile paraaortik LAP'lardan yapılan ADC ölçümleri benzerlik göstermektedir.

Hepatoselüler karsinomların ortalama $\mathrm{ADC}$ değeri $1,14 \pm 0,13 \quad \times 10^{-3}$ $\mathrm{mm}^{2} / \mathrm{s}$ olarak ölçülmüş olup komşu karaciğer parankimi ortalama ADC değerleri ile karşılaştırıldığında (Tablo 3) aralarında istatiksel olarak anlamlı fark bulunamadı (Şekil 6) .

Tablo 3. HCC ve Komşu karaciğer parankiminin ortalama ADC değerleri

\begin{tabular}{|c|c|}
\hline $\begin{array}{c}\text { HCC ort. ADC } \\
\text { Değerleri }\left(\mathrm{mm}^{2} / \mathrm{s}\right)\end{array}$ & $\begin{array}{c}\text { Komșu karaciğer } \\
\text { parankimi ort. ADC } \\
\text { Değerleri }\left(\mathrm{mm}^{2} / \mathrm{s}\right)\end{array}$ \\
\hline $1,182 \times 10^{-3} \mathrm{~mm}^{2} / \mathrm{s}$ & $1,031 \times 10^{-3} \mathrm{~mm}^{2} / \mathrm{s}$ \\
\hline $0,998 \times 10^{-3} \mathrm{~mm}^{2} / \mathrm{s}$ & $0,876 \times 10^{-3} \mathrm{~mm}^{2} / \mathrm{s}$ \\
\hline $1,241 \times 10^{-3} \mathrm{~mm}^{2} / \mathrm{s}$ & $1,123 \times 10^{-3} \mathrm{~mm}^{2} / \mathrm{s}$ \\
\hline
\end{tabular}




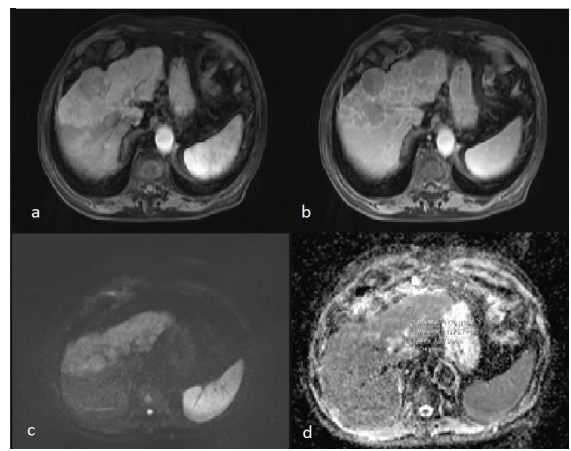

Şekil 6. Siroz zemininde karaciğer sol lob ve sağ lob anteriorunu içine alan HCC. Aksiyel planda arteryal faz (a) ve geç faz kontrastlı T1 AG GE (b) sekansları, b $800 \mathrm{~s} / \mathrm{mm}^{2}$ DAG (c) ve ADC haritası (d).Arteryal fazda belirgin kontrastlanırken geç fazda 'wash out' izleniyor.DAG'de hiperintens,ADC haritasında hafif hipointens sinyal özelliğinde.ADC değeri $1.279 \times 10^{-3} \mathrm{~mm}^{2} / \mathrm{s}$ olarak ölçüldü.

Tüm benign ve malign lezyonların ortalama ADC ölçümlerini karşılaştırdığımızda fark istatistiksel olarak anlamlı bulundu. $(\mathrm{P}<0.001)$

\section{TARTIȘMA}

Çalışmamızda temel düşüncemiz karaciğer fokal kitlesi olan hastalarda intravenöz kontrast madde vermeden DAG ve ADC haritalama ile benign ve malign ayrımı yapilabilir mi sorusuna yanıt aramaktı. $\mathrm{Bu}$ amaçla sık görülen karaciğer kitlelerinde rutin konvansiyonel sekansların yanında DAG'lardaki sinyal özelliklerini inceledik ve ADC değerlerini hesapladik.

Dokudaki difüzyonu ölçebilmek için eko planar görüntüleme sekansında 180 derecelik RF pulsu öncesi ve sonrasına olmak üzere güçleri ve süreleri eşit iki adet gradiyent (difüzyon gradiyentleri) eklenir. Gradiyentler difüzyona bağlı hareketi belirleyebilecek kadar güçlü olmalıdır. Difüzyon ağırlık faktörü yani $b$ değeri sekansın difüzyona ne kadar duyarlı olduğunu gösterir. İntravasküler alandaki suyun hareketi en belirgin difüzyon hareketidir ve uzun bir difüzyon mesafesi vardır. $\mathrm{Bu}$ nedenle biz bu difüzyonu düşük $b$ değerleri ile gösterebiliriz. Buna karşıllik yavaş hareket eden su moleküllerini veya az mesafe kat eden su moleküllerinin difüzyonunu yüksek $b$ değerleri ile gösterebiliriz (3). Çalışmamızda yüksek b değerleri seçerek sekansın difüzyon duyarlılığını arttırmayı ve perfüzyon etkisinden maksimum derecede kaçınmayı amaçladık.

Karaciğerin en sık görülen benign lezyonu hemanjiomdur (9). Hemanjiomlarda görüntüleme yöntemleri ile kesin tanıya gitmek mümkündür $(9,10)$. Ancak bazı hastalar uzun süre kapalı ortamda kalamadıkları için tetkik kısa sürede bitirilmek zorunda kalınabilir veya kontrast maddeye karş1 aşırı duyarlılıkları olan hastalarda inceleme kontrastsiz yapilmak zorunda kalınabilir. Hatta bazı hemanjiomlar tipik kontrastlanma paternlerinin aksine atipik kontrastlanma gösterebilirler. Konvansiyonel sekanslar ve kontrastlı imajlarla malign lezyonlardan ayrımları mümkün olmaz. Böyle durumlarda difüzyon ağırlıklı görüntüler ayırıcı tanı yapmada yardımcı olabilir.

Çalışmamızda kontrastlı inceleme sonras1 kesin olarak hemanjiom tanısı alan tüm kitleler difüzyon ağırlıklı imajlarda ve ADC haritasında hiperintens izlendi. Yani difüzyon kisitlilığ1 saptanmadı. Difüzyon ağırlıklı sekanslarda hiperintens olmaları T2 etkisine bağlı olarak değerlendirildi $(1,3,8)$. Bu kitlelerden ölçülen ortalama ADC değeri $1,98 \pm 0,38 \times 10^{-3} \mathrm{~mm}^{2} / \mathrm{s}$ olarak bulundu. Basit kistlerde difüzyon kisttlllığ 1 izlenmemekte olup ADC değeri $2,65 \pm 0,54 \times 10^{-3} \mathrm{~mm}^{2} / \mathrm{s}$ olarak bulundu. Tüm basit kistlerde ölçülen ADC değerleri hemanjiomlardan ölçülen ADC değerlerinden yüksekti ancak aralarında istatiksel olarak anlamlı farklılik saptanmadi. Namimoto ve arkadaşlarının 1997'de yayınladıkları fokal karaciğer kitlelerinin karakterizasyonunda difüzyon MR görüntülemenin kullanımı ile ilgili çalısmada belirttiği gibi, hemanjiomların $\mathrm{ADC}$ değerlerinin kistlere göre daha düşük olmasının sebebi kanın kist sıvısına göre daha visköz olması ve hemanjiomda multipl interstisyel boşluk, skar ve kan elemanları varlığı olabilir.

Karaciğerin benign lezyonlarından biri de özellikle ülkemizde endemik olan kist hidatiktir. İnan ve ark. (11) yaptığ çalışmada basit kist ve kist hidatik ADC değerleri arasında istatiksel olarak anlamlı farklılık bildirilse de bizim çalışmamızda anlamlı farklılık saptanmamıştır $(p>0,05)$. Bunun nedeni vaka sayımız sinırli olsa da çalışmamıza tip -4 ve -5 kist hidatik lezyonlarını da katmamız olabilir.

FNH olarak tanı alan kitlemizin ortalama ADC değeri normal karaciğer parankimi ortalama ADC değeri ile karşılaştırıldığında Taouli ve arkadaşlarının (12) 2003'de yayınladıkları çalışmadakine benzer olarak belirgin farkl1lık göstermemektedir. Bunun nedeni histopatolojik olarak FNH'nın hepatosit, kupffer hücresi gibi normal karaciğer hücreleri içermesi ve normal karaciğer parankiminden tek farkının dezorganize bir hiperplazi varlığı olması olabilir. (13, 14) Ancak çalışmamızda fokal nodüler hiperplazili tek vaka yer alması bu konuda belirgin kisitlilik oluşturmaktadır.

Hepatik abseler nekrotik malign lezyonlardan ancak görüntüleme 
bulgularının klinik ve laboratuvar bulguları ile desteklenmesiyle ayırt edilir. Difüzyon ağırlıklı görüntülemeler abse tanısını koymada ve nekrotik tümörleri ayırt etmede yardımcı olabilir mi düşüncesinden yola çıkarak yeni çalışmalar yapılmaktadır. Chan ve ark. (15) 2001'de yayınladikları çalışmada beş piyojenik ve bir fungal absede kısıtlanmış difüzyon izlemişler ve ortalama ADC değerini $0,35-0,67 \times 10^{-3} \mathrm{~mm}^{2} / \mathrm{s}$ olarak bulmuşlardır. Konstantin ve ark. (16) ise 2007'de yayınladikları çalışmada (16) abselerin evresine göre ADC değerlerinin değiştiğini bildirmişlerdir. Bu çalışmada erken evre abse formasyonlarının ADC değerlerinin tümörlerle karışabileceği ancak geç evrede ADC değerleri belirgin yükselerek ayırt edilebildiği bildirilmektedir. Her iki çalışmada da genel olarak baktığımızda abse formasyonları difüzyon ağırlıklı sekanslarda kısitlilik göstermekte ve ADC değerleri $1.00 \times 10^{-3} \mathrm{~mm}^{2} / \mathrm{s}^{\prime}$ nin altındadır. Çalışmamızda bir piyojenik abse vakası yer almakta olup ortalama ADC değeri 0,984 x $10^{-3} \mathrm{~mm}^{2} / \mathrm{s}$ olarak ölçülmüştür. $\mathrm{Bu}$ değer diğer çalışmalardaki sonuçları destekler nitelikte malign tümörlerin ADC değerleri ile örtüşmektedir (Şekil 7).

Çalışmamızdaki malign kitlelerin ortalalama ADC değeri $0,729 \times 10^{-3}$ $\mathrm{mm}^{2} / \mathrm{s} \quad$ olarak ölçülmüştür. Metastazlar ile HCC'leri karşılaştırdığımızda metastazların ortalama ADC değerleri daha düşüktür. Metastazlar içinde de daha önce belittiğimiz gibi non-Hodgkin lenfoma vakasında en düşük ADC değeri ölçülmüş olup bu da bu tümörlerdeki yüksek selülariteye bağlı olarak değerlendirilmiştir (1). HCC'lerın ADC değerleri komşu sirotik karaciğer parankimine benzer olarak ölçülmüş olup literatür ile uyumlu olarak değerlendirilmiştir $(6,12,17)$. HCC'ler büyüme paternlerine

ve diferansiyasyonlarına göre siniflandirilirlar. İyi diferansiye HCC'lar tamamen hepatositlere benzeyen kordonlar veya küçük yuvarlak şekilde dizilmiş hücrelerden oluşur. Bu hücrelerin sitoplazmalarında safra globülleri, Mallory cisimciklerini taklit eden asidofilik hiyalin inklüzyonlar bulunur (18). Bizim vakalarımızda kitlelerin ADC değerlerinin komşu parankimle benzer olması HCC'lerın iyi diferansiye olmalarına bağlı olabilir.

Taouli 2003'de (12) ve Kim 1999'da (5) yayımladıkları çalışmalarda benign ve malign lezyonların ayrımında eşik değer olarak $1,5 \times 10^{-3} \mathrm{~mm}^{2} / \mathrm{s}$ değerini baz almışlardır. Çalışmamızı bu yönde değerlendirdiğimizde; HCC'lerin
ADC değerleri komşu karaciğer parankimi ile benzerlik gösterse de bu eşik değerinin altındadır. Yine hemanjiom, basit kistler, FNH ve hidatik kist ADC değerleri, tanımlanan bu eşik değeri üstünde yer alırken benign lezyonlardan sadece absenin ortalama ADC değeri bu eşik değerinin altında kalmaktadır. Çalışmamızda yer alan tüm malign lezyonların ADC değerleri bu eşik değer altında yer aldığı için bu değerin benignmalign ayrımında yardimc1 olabileceğini düşünüyoruz.

Çalışmamızın en önemli sınırlılığı vaka sayımızın az olması ve benzer çalışmaların literatürde yer almasıdır. Ancak çalışmamız literatürdeki çalışmalarla uyumlu olarak bu çalışmaları desteklemektedir. Çekimlerde difüzyon ağırlıklı imajların rutin olarak konvansiyonel sekanslara eklenmesinin yararlılığını göstermesi açısından bir adım daha atılması konusunda önemli olduğunu düşünmekteyiz.

Sonuç olarak, karaciğerde $1 \mathrm{~cm}$ 'den büyük fokal lezyonlarda, difüzyon ağırlıklı görüntüleme; birçok teknik sinırlılıklarına rağmen, benign-malign ayrımında bize ek bilgiler sağlayan ve intravenöz kontrast madde kullanımını azaltabilecek bir yöntemdir.

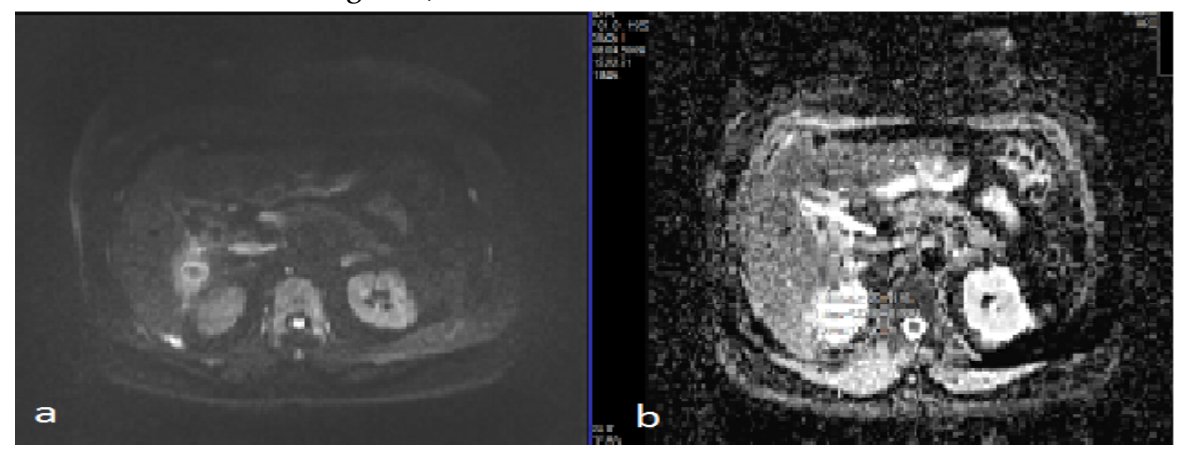

Şekil 7. Kolesistektomi operasyonu sonrası karaciğer sağ lob posteroinferior segmentte abse formasyonu. Aksiyel planda b $800 \mathrm{~s} / \mathrm{mm}^{2}$ DAG (a) ve ADC haritası (b). ADC haritasında hafif hipointens karakterde difüzyon kısıtlıığı izleniyor. 


\section{KAYNAKLAR}

1. Koh D, Collins D. Diffusion Weighted MRI in the Body: Applications and Challenges in Oncology. Am J Roentgenol 2007;188:1622-1635.

2. Reimer P, Saini S et al. Clinical application of abominal echoplanar imaging (EPI):optimization using a retrofitted EPI system. J Comput Asist Tomogr 1994;18:673-679.

3. Stejskal EO, Taner JE. Spin diffusion measurements: spin-echo in the presence of a time dependent field gradient. J Chem Phys 1965;42:288292.

4. Ichikawa T, Haradome H, Hachiya J, et al. Diffusion-weighted single shot echoplanar sequence: detection and characterization of focal hepatic lesion. AJR 1998;170:397-402.

5. Kim T, Murakami T, Takahashi S.Diffusion weighted single shot echoplanar MR imaging for liver disease. Am J Roentgenol 1999;173:393-398.

6. Namimoto T, Yamashita $\mathrm{Y}$, et al. Focal Liver Masses: Characterization with Diffusion-weighted Echo-Planar MR Imaging. Radiology 1997;204:739744.
7. Turgut AT, Akhan O, et al. Sonographic Spectrum of Hydatid Disease. Ultrasound Quarterly 2008;24:17-19.

8. Taouli B, Koh D, et al. Diffusionweighted MR Imaging of the Liver. Radiology 2010; 254: 47-66.

9. Shaid H. Liver MRI Correlation with Other Imaging Modalities and Histopathology. Springer; 2007;1:16-26

10. Hussain SM, Semelka RC. Liver masses. Magn Reson Imaging Clin $\mathrm{N}$ Am 2005;13:255-275.

11. Inan N, Arslan A, et al. Diffusionweighted MR imaging in the Differantial Diagnosis of Simple and Hydatid Cysts of the Liver. AJR 2007;189:1031-1036.

12. Touli B, Vilgrain V, Dumont E, et al. Evaluation of liver diffusion isotrophy and characterization of focal hepatic lesion with two single shot echo-planar MR imaging sequences: prospective study in 66 patients. Radiology 2003;226:71-78.

13. Hussain SM, Terkivatan T, Zondervan PE, et al. Focal Nodular Hyperplasia: a spectrum of findings at state of the art
MR imaging, ultrasound, CT and pathology. Radiographics 2004;24:3-19.

14. Finley A, Hosey J, Noone T, et al. Multiple focal nodular hyperplasia syndrome: diagnosis with dynamic, gadolinium-enhanced MRI. MRM 2005; 23:511-513

15. Chan JH, Tsui EY, Luk $\mathrm{SH}$ et al. Diffusion-weighted MR imaging of the liver: distinguishing hepatic abscess from cyctic or necrotic tumor. Abdominal Imaging 2001; 26:161-165.

16. Holzapfel K, Rummeny E, Gaa J. Diffusion-weighted MR imaging of hepatic abscesses: possibility of different apparent diffusion coefficient (ADC)-values in early and mature abscess formation. Abdominal Imaging 2007; 32:538-539.

17. Müller MF, Prasad P, Siewert B. Abdominal diffusion mapping with use of a whole-body echo-planar system. Radiology 1994;190:475-483.

18. Kumar V, Cotran R, Robbins S, Basic Pathology. 6th ed. W. B. Saunders Company;2005;19:607-643. 
